\title{
Methods for in Situ Electroluminescence Imaging of Photovoltaic Modules under Varying Environmental Conditions
}

Owen-Bellini, Michael; Sulas-Kern, Dana B.; Perrin, Greg; North, Hannah; Spataru, Sergiu; Hacke, Peter

Published in:

IEEE Journal of Photovoltaics

Link to article, DOI:

10.1109/JPHOTOV.2020.3001723

Publication date:

2020

Document Version

Peer reviewed version

Link back to DTU Orbit

Citation (APA):

Owen-Bellini, M., Sulas-Kern, D. B., Perrin, G., North, H., Spataru, S., \& Hacke, P. (2020). Methods for in Situ Electroluminescence Imaging of Photovoltaic Modules under Varying Environmental Conditions. IEEE Journal of Photovoltaics, 10(5), 1254-1261. https://doi.org/10.1109/JPHOTOV.2020.3001723

\section{General rights}

Copyright and moral rights for the publications made accessible in the public portal are retained by the authors and/or other copyright owners and it is a condition of accessing publications that users recognise and abide by the legal requirements associated with these rights.

- Users may download and print one copy of any publication from the public portal for the purpose of private study or research.

- You may not further distribute the material or use it for any profit-making activity or commercial gain

- You may freely distribute the URL identifying the publication in the public portal 


\title{
Methods for In Situ Electroluminescence Imaging of Photovoltaic Modules Under Varying Environmental Conditions
}

\author{
Michael Owen-Bellini, Dana B. Sulas-Kern, Greg Perrin, Hannah North, Sergiu Spataru, Peter Hacke
}

\begin{abstract}
Electroluminescence (EL) imaging is a powerful tool used to identify defects in photovoltaic (PV) solar cells. Typically, this type of characterization is performed in the dark using a current injection that equals short-circuit current measured at standard test conditions (STC). Restricting imaging to such a temperature range limits the information obtained about the module and cells. However, it is not trivial to develop a tool that would allow for EL imaging to be performed under a wider range of temperatures. Here we demonstrate an in-situ EL imaging capability developed within an environmental chamber that allows for control of sample temperatures between $-40^{\circ} \mathrm{C}$ and $90^{\circ} \mathrm{C}$. Additionally, we demonstrate EL imaging of 4-cell minimodules (MiMo) under front-side mechanical loading. A Raspberry Pi-connected camera with short-pass filter removed is used for EL imaging. The camera is low-cost with a small formfactor, appropriate for use in a harsh, enclosed environment. The camera is installed within a thermally isolating housing mounted within the environmental chamber. Three example cases are given for MiMos that exhibit various forms of degradation including solder fatigue and cell cracking. It is shown that by measuring at conditions above and below STC, different behaviors may be identified. In some cases, restricting characterization to STC may lead to a failure to detect damage existing in the sample.
\end{abstract}

Index Terms - Combined-Accelerated Stress Testing, DuraMAT, Electroluminescence, Module Characterization

\section{INTRODUCTION}

$\mathrm{P}$ hotovoltaic (PV) solar cells are susceptible to a wide range of defects that can negatively affect their performance. Many of these defects may be detected using a technique known as electroluminescence (EL) imaging whereby a PV cell will emit near-IR light in response to a forward-bias electric current that may be captured with an appropriate detector. It is common practice to perform laboratory EL imaging at module temperatures between 20 and $30^{\circ} \mathrm{C}$, as specified by the International Electrotechnical Commission (IEC) 60904-13 standard [1].

Solar cell cracks are common in Si-based PV modules [2], [3]. Cell cracks do not always lead to substantial power loss except when they propagate enough to sever all the metallization connections in a given area, leading to a cell area disconnect [4]. It is recognized, however, that subsequent environmental aging is likely to propagate cracks such that they do become more problematic later. Solder bond and ribbon interconnect fatigue are also commonly reported failure modes in PV modules [8], the primary drivers for which are thermal cycling and mechanical loading. It is well understood that cells and other components in a PV module undergo displacement as a result of temperature change due to the various mismatching coefficients of thermal expansion (CTE) [5]. This displacement could lead to an expansion of cell cracks and greater power loss. Therefore, restricting module characterization to a single temperature point limits the useful information gained about the module. Previous work by D2 Solar, BrightSpot Automation and the Florida Solar Energy Center (FSEC) has demonstrated the importance of evaluating PV module reliability outside the STC temperature value of $25^{\circ} \mathrm{C}$, particularly regarding cell cracking at lower temperatures [6].

Performing EL imaging at a wider range of temperatures can reveal much more information about the performance of a module and the possible hidden defects that may not be observable at STC temperatures. Additionally, having the ability to perform frequent EL imaging in situ allows for a better understanding of the initiation and progression of various degradation modes during accelerated aging. To this end, an EL imaging capability has been developed within an environmental chamber used for combined-accelerated stress testing (C-AST) [9]. Typically, EL imaging is performed using expensive charge-couple devices (CCD) which are relatively large. Mounting such devices within an environmental chamber (which may operate at extreme temperatures and relative humidity $(R H)$ ) is not trivial and presents a significant risk of damage to the device. Here we identify a low-cost and low-profile camera solution which can be mounted within a thermally stable and moisture resilient housing. The housing minimizes risk of damage to the camera, which itself is lowcost. The developed capability enables module characterization within a dynamic test environment, allowing for imaging at the extremes of the test temperatures ranging from $-40^{\circ} \mathrm{C}$ to $90^{\circ} \mathrm{C}$. Additionally, the capability allows for imaging with front-side mechanical loading. Details of the test equipment are given so that the capability can be reproduced.

This paper enhances a previous conference proceeding [10] with additional demonstration of the electroluminescence capability and the inclusion of EL imaging below $0^{\circ} \mathrm{C}$ and with front-side mechanical loading. In addition, there is an expanded description of the applied methods and experimental setup. 


\section{EXPERIMENTAL SETUP}

\section{A. Environmental Chamber}

The in situ EL capability was developed within an existing Atlas XR-260 environmental chamber. The chamber has been modified for C-AST and is capable of housing up to six 4-cell PV mini-modules (MiMos) that are $34 \mathrm{~cm} \times 37 \mathrm{~cm}$. Test modules are seated horizontally in rigid, polytetrafluoroethylene (PTFE)-enveloped steel frames. Four water-cooled xenon arc lamps are mounted about $0.6 \mathrm{~m}$ above the sample plane alongside water spray nozzles. Air temperature is controlled between $-40^{\circ} \mathrm{C}$ and $90^{\circ} \mathrm{C}$ and relative humidity $(\mathrm{RH})$, between $<5 \%$ and $97 \%$ using a Watlow F4 controller. Sample temperatures are monitored via T-type thermocouples attached to the rear surface of the test samples (two per sample) and recorded using a National Instruments (NI) 9211 analogue-to-digital converter (ADC) module. Displacement-controlled mechanical loading is delivered to the samples via $100 \mathrm{~mm}$ diameter PTFE-encased steel rings powered by $72.6 \mathrm{~mm}$ bore Bimba pneumatic actuators. The required displacement is determined by loading a horizontally mounted, 60-cell module to the desired level (e.g. $2400 \mathrm{~Pa}$ ) and measuring the vertical displacement along its surface. The maximum displacement at the center of the module is used as the displacement of the mechanical loading rings in the chamber. Finite-element models are currently being developed by Hartley and Meert to validate the mechanical loading method and bending moments applied to MiMos in C-AST [11][12]. The loading rings cause partial shading on the sample surface. A Keithley 2651a Source Measure Unit (SMU) is used for current injection for EL imaging. Only one SMU is being used, so a switching network was developed such that the modules on each of the six channels may be switched from their default state (i.e. connected to the load resistor) to a temporary state connecting them to the SMU one at a time. For each channel, a Gigavac G12SP and Gigavac G8SPD is used to switch the current channel and voltage sense channel, respectively. Relay switching is controlled via NI LabVIEW and a NI 9174 compact data acquisition (cDAQ) chassis with NI 9678 data DAQ module. Automatic control and monitoring of all sub-systems is achieved using NI LabView. Additional details for the C-AST tool and the control programming are described by Spataru et al. [13]. A top-down schematic inside layout of the test chamber is given in Fig. 1. and a total view of the outside of the chamber is given in Fig. 2.

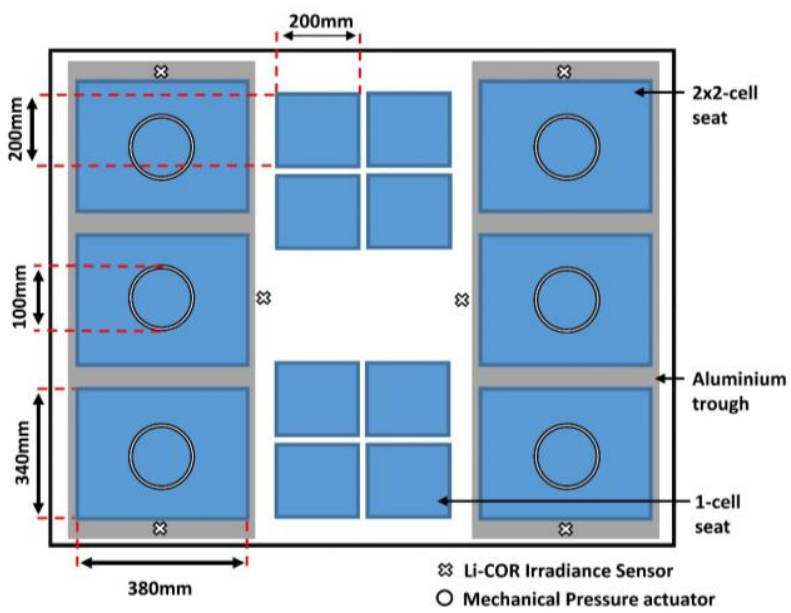

Fig. 1. Top-down schematic of the Atlas XR-260 climate chamber showing positioning for test samples, mechanical loading actuators and LI-COR pyranometers

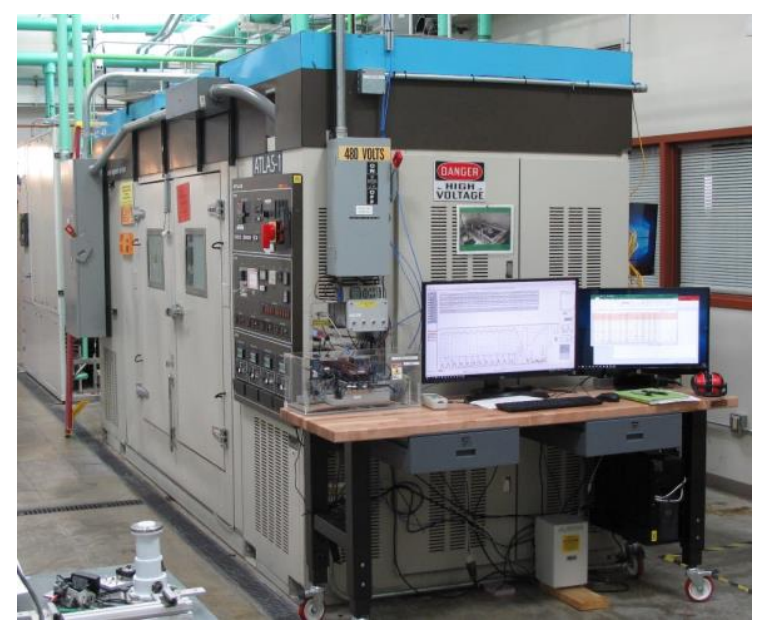

Fig. 2. Outside view of the Atlas XR-260 weathering chamber used for in situ electroluminescence imaging and combined-accelerated stress testing

\section{B. Camera Housing}

A thermally isolating housing was developed to protect the camera from the extreme conditions of the chamber. The housing is milled from polytetrafluoroethylene (PTFE) and features a borosilicate glass front cover that is heated above dew point using five $15 \mathrm{Ohm}$ resistors at $13.7 \mathrm{~V}$ to dissipate a total $2.5 \mathrm{~W}$ to mitigate condensation at low chamber temperatures. The camera is mounted to a copper heatsink that is hollowed out to allow for ethylene glycol coolant to pass through. The coolant is temperature-regulated using a Thermo Scientific Neslab Thermoflex recirculating chiller. An image of the housing is given in Fig. 3. The thermal control maintains a camera temperature of $25^{\circ} \mathrm{C} \pm 3^{\circ} \mathrm{C}$ under all chamber conditions which is measured using a T-type thermocouple attached directly to the lens housing. Additionally, the entire housing is covered with aluminum sheet metal to reflect irradiance from the xenon arc lamps. This helps reduce the housing temperature but also helps to mitigate the housings impact on shading within the chamber. Each housing is 
mounted to the ceiling of the chamber using polyparaphenylene terephthalamide rope, which helps to reduce the transfer of chamber vibrations to the camera and improve image quality.
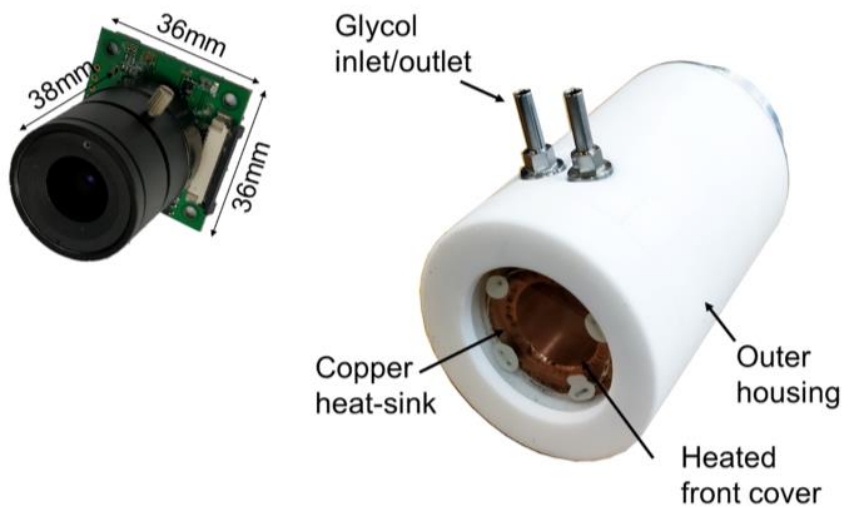

Fig. 3: EL camera with lens and thermally isolating camera housing for mounting within the climate chamber [10]. The Al reflector placed around the cylinder is not shown.

\section{Camera}

An ArduCam NOIR 8MP IMX219 camera module was used as a low-cost and low-profile imaging solution, which was desirable given the risk of damage from exposure to the extreme environmental conditions of the chamber. Its small form factor allows it to be mounted within a thermally isolating housing which itself is mounted inside the C-AST chamber above the sample plane. The camera consists of a Sony IMX219PQ 8.08Mpixel complimentary metal-oxidesemiconductor (CMOS) sensor without a long-pass filter, allowing for imaging at the near-infrared (NIR) range. The sensor has an active pixel count of $3296 \times 2512$ with pixel size $1.12 \mu \mathrm{m} \times 1.12 \mu \mathrm{m}$. The ArduCam camera and lens measures $36 \mathrm{~mm} \times 36 \mathrm{~mm} \times 38 \mathrm{~mm}$ (Fig. 3). A total of six cameras are mounted within the chamber, one above each of the MiMo seats. The cameras are mounted approximately $0.6 \mathrm{~m}$ above the sample plane. To capture the full active cell area of the MiMos at that distance, an ArduCam LS-2718CS lens was used that has a $70^{\circ}$ field-of-view (FOV). The cameras interface directly with a Raspberry Pi (RPi) 3 model B+ microcontroller, which performs imaging using a Python script and PiCamera library. The RPis operate independently of the main LabVIEW control software and a task scheduling software (Cron) is used to periodically search for a comma separated value (csv) file which contains imaging parameters including timestamp, exposure time, number of images, and more. If a parameter file is present, Cron instructs the RPi to perform imaging using the Python script according to the parameters contained within. Imaging is automated as part of the experiment via LabVIEW, which constructs the parameter file based on the experiment requirements and transfers the file to the RPi using a secureshell (SSH) communication protocol. Current-injection is supplied to the test sample using the SMU immediately prior to transfer of the parameter file and remains on until instructed otherwise. A general-purpose input/output (GPIO) pin on the RPi board is connected to a NI USB 6008, which is read by NI LabVIEW. At the end of imaging, the Python script instructs the GPIO pin to send a signal which in turn instructs LabVIEW to switch off the current-injection. The RPi PiCamera library limits exposure time to $10 \mathrm{~s}$. However, in most cases, this has not hindered the quality of the images and in some cases a $10 \mathrm{~s}$ exposure leads to over-exposure of the image.

The wide-angle lens introduces lens (barrel) distortion to the images, where edges of the module are made to appear curved. Additionally, the presence of the xenon arc lamps and other hardware on the chamber ceiling limits the mounting possibilities of the camera such that the cameras cannot always sit directly above the center of the module, thus introducing some tangential distortion to the images. For each position in the chamber, the camera may be calibrated to correct for these distortions. The method described by Bedrich et al [14] is applied whereby a chessboard pattern is used to extract distortion coefficients $\mathrm{k}_{1}, \mathrm{k}_{2}, \mathrm{p}_{1}, \mathrm{p}_{2}$ and $\mathrm{k}_{3}$, which may then be used to correct a distorted image. Barrel distortion is corrected using Eq. (1) and (2) where tangential distortion is corrected using Eq. (3) and (4). Here, $x$ and $y$ are the coordinates of a single pixel and $\mathrm{X}_{\text {corrected }}$ and $\mathrm{Y}_{\text {corrected, are the new pixel }}$ coordinates after corrections have been applied. Lens distortion correction is implemented using the OpenCV Python library [15].

$$
\begin{array}{r}
\mathrm{X}_{\text {corrected }}=\mathrm{x} \times\left(1+\mathrm{k}_{1} \mathrm{r}^{2}+\mathrm{k}_{2} \mathrm{r}^{4}+\mathrm{k}_{3} \mathrm{r}^{6}\right) \\
\mathrm{Y}_{\text {corrected }}=\mathrm{y} \times\left(1+\mathrm{k}_{1} \mathrm{r}^{2}+\mathrm{k}_{2} \mathrm{r}^{4}+\mathrm{k}_{3} \mathrm{r}^{6}\right) \\
\mathrm{X}_{\text {corrected }}=\mathrm{x}+\left[2 \mathrm{p}_{1} \mathrm{xy}+\mathrm{p}_{2}\left(\mathrm{r}^{2}+2 \mathrm{x}^{2}\right)\right] \\
\mathrm{Y}_{\text {corrected }}=\mathrm{y}+\left[\mathrm{p}_{1}\left(\mathrm{r}^{2}+2 \mathrm{y}^{2}\right)+2 \mathrm{p}_{2} \mathrm{xy}\right]
\end{array}
$$

An example of the distortion coefficient extraction method and subsequent application to EL imaging is given in Fig. 4. A raw image of a printed chessboard pattern, Fig. 4(a), is used to determine the distortion coefficients. An example EL image, Fig. 4(c), is then corrected using the extracted distortion coefficients to produce the corrected image, Fig. 4(d). This process is repeated for each camera in the chamber. 


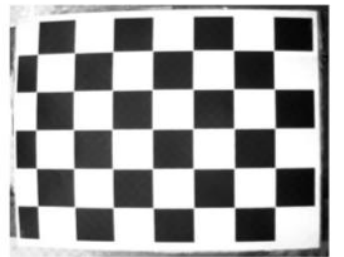

(a)

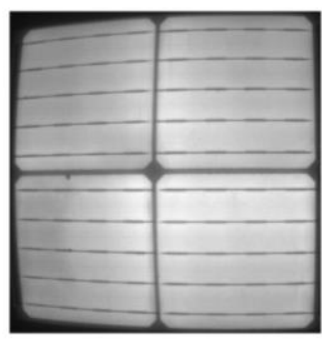

(c)

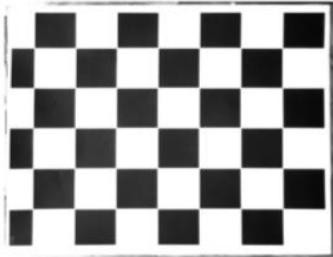

(b)

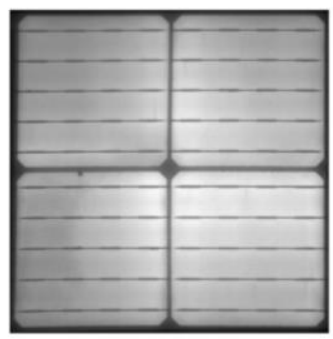

(d)
Fig. 4. (a) Raw image of chessboard pattern image used for distortion coefficient extraction (b) corrected chessboard image (c) raw EL image of 4cell module, (d) and corrected image using lens correction determined through chessboard pattern.

\section{Noise Reduction and Outlier Removal}

Image stacking is commonly used in astrophotography to reduce digital noise from long exposures. The basic principle is that bright points in the image that represent a real signal become brighter with each additional stacked image as the number of counts increases for that point. This increases the contrast of that point. Here we implement a median stacking method whereby images are loaded into an $\mathrm{x}-\mathrm{y}$ matrix that is $\mathrm{n}$ levels deep. Once the matrix is full, the NumPy Python library $[16]$ is used to call a median function to determine the median value of each pixel in the matrix.

Outliers may also be present in the captured images. These are typically caused by single-time-effects (STE) [17] and are easily identified and removed by determining a median value for each pixel between all captures in the stack.

\section{E. Full-size module imaging}

An EL image for a 60-cell crystalline-silicon (c-Si) module was captured using the aforementioned setup (without the thermally isolating housing) for a 60-cell c-Si module (Fig.4.). A single ArduCam camera was used, mounted at a distance of 2 meters from the module. Air temperature was measured to be $24.8{ }^{\circ} \mathrm{C}$ in the imaging room, where the module had been resting for more than 24 hours. Cell cracks and other features are identifiable in the image, including the identification of a severely damaged cell. This demonstrates the hardware's feasibility for detecting defects and failures in full-sized PV modules. While the wide-angle lens was used with applied corrections for the image shown in Fig. 5., alternative ArduCam lenses with lower FOVs are commercially available that could eliminate the need for large lens distortion corrections, provided that the camera could be mounted at a sufficient distance to fit the module within the FOV.

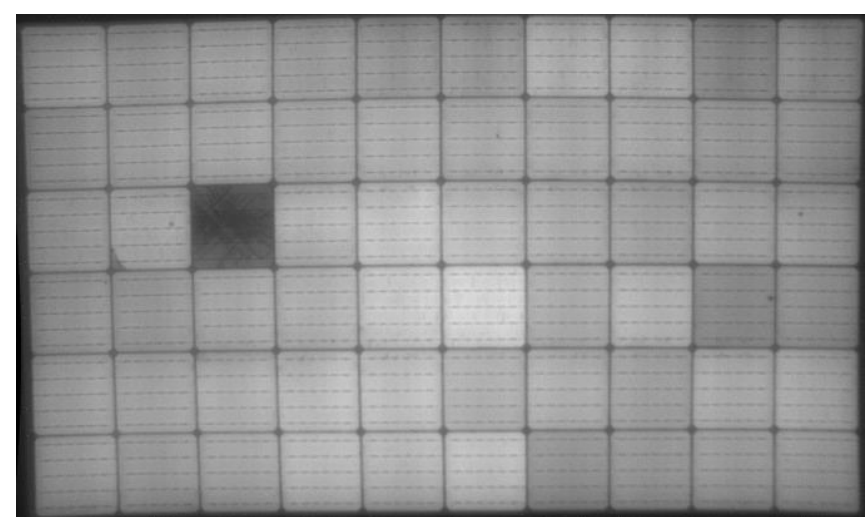

Fig. 5. EL image for 60-cell c-Si module with $40.1 \mathrm{~V}$ and $8.37 \mathrm{~A}$ injection with an exposure time of $9 \mathrm{~s}$.

\section{CAPABILITy DEMONSTRATION}

Three examples are given here to demonstrate the hardware capabilities and to highlight the importance of characterizing module behavior outside the STC temperature value of $25^{\circ} \mathrm{C}$. In each example, MiMos of different constructions and varying degrees of damage are used for temperature-dependent and mechanical loading-dependent EL imaging. All MiMos are 4-cell in a $2 \times 2$ configuration.

\section{A) Example 1}

A monocrystalline silicon cell MiMo with glass front and back was subjected extreme mechanical loading (>5400 Pa) in the C-AST chamber sufficient to result in severe cracking of all cells and both glass surfaces; see Fig. 6 . The device is used here as a demonstration of the capabilities of the in-situ EL camera within the chamber. The air temperature of the chamber was ramped from $-40^{\circ} \mathrm{C}$ to $80^{\circ} \mathrm{C}$ in $30^{\circ} \mathrm{C}$ increments. After each temperature step, the module temperature was allowed to stabilize for 10 minutes. A current injection of $9.3 \mathrm{~A}$ was used for EL images with an exposure time of 9 seconds. The graphic in Fig. 6. focuses on one area of the module to highlight the change in crack width during the temperature sweep. As module temperature increases, the disconnected areas of the cell are also increasing. This can be attributed to the effects of thermal expansion such that with increasing temperature, the laminate expands which in turn displaces the cells, increasing the cell crack widths which may result in connection losses [5] . EL characterization of PV modules is typically performed at $25^{\circ} \mathrm{C} \pm 1{ }^{\circ} \mathrm{C}$ [1]. Certification of a PV module following accelerated aging according to the IEC 61215-series standard [18] is dependent on electrical characterization at a repeatable specimen temperature (within $\pm 1^{\circ} \mathrm{C}$ ) in the range $25^{\circ} \mathrm{C}-50$ ${ }^{\circ} \mathrm{C}$. Here we show that by limiting module characterization post-aging to a single temperature condition, it is possible to underestimate the impact of damage induced. This is particularly important when taking into account that modules often operate at temperatures above STC in the field [19][20]. 


\section{B) Example 2}

A test MiMo provided by TesSolar Inc. was subjected to C-AST for 24 weeks of the Tropical test protocol described in [21]. The MiMo consists of multi-crystalline Si back surface field (BSF) cells interconnected with soldered conductor ribbons laminated using a poly(ethylene-co-vinyl acetate) (EVA) encapsulant, a polyamide-based backsheet and glass front cover. Lamination was performed at $145^{\circ} \mathrm{C}$ and $1 \mathrm{~atm}$ of pressure for 8 minutes. Further details of the MiMo construction and testing protocol are described by Hartman et al [22], where the MiMo is referred to as "Mini-Module C". During testing, the MiMo suffered cell cracking and apparent interconnect damage, which is evident from the presence of current-crowding around the top ribbon of the upper-right cell (Fig. 7.). The damaged location was identified as being the joint between the bottom cell ribbon (of the upper-right cell) and the busbar. Applying pressure to this joint using a clamp removed the current-crowding effect observed in EL, suggesting that connection could be re-established. While this suggests that the specific solder joint is damaged, the observed current-crowding could also be the product of a damaged interconnect ribbon. Again, for demonstration purposes with the pressure actuator removed, EL imaging is conducted on this MiMo during five thermal cycles between $-40^{\circ} \mathrm{C}$ to $80^{\circ} \mathrm{C}$ in steps of $30^{\circ} \mathrm{C}$. A current-injection $9.3 \mathrm{~A}$ and $9 \mathrm{~s}$ exposure time are used. Module temperature is allowed to stabilize for 10 minutes prior to each image. Fig. 7 shows EL images from the third cycle. EL intensity around the top busbar of the upperright cell increases with increasing temperature to suggest that the solder bonds further degrade to reduce conductivity. At lower temperatures $\left(<50^{\circ} \mathrm{C}\right)$, the effect of solder fatigue is much less evident. A likely explanation to this is the effect of thermal expansion, whereby lower temperatures lead to shrinkage and an overall contraction of the module laminate which reestablishes contact of the degraded solder joint or interconnect ribbon in a similar manner to applying pressure with a clamp [23]. Conversely, increased temperatures lead to an expansion of the laminate, separating the solder from the pad. Like example 1, the results in Fig. 7 show that restricting module characterization to $25^{\circ} \mathrm{C}$ could lead to an underestimation of damage and performance loss in modules following accelerated aging or, in this case, could result in a
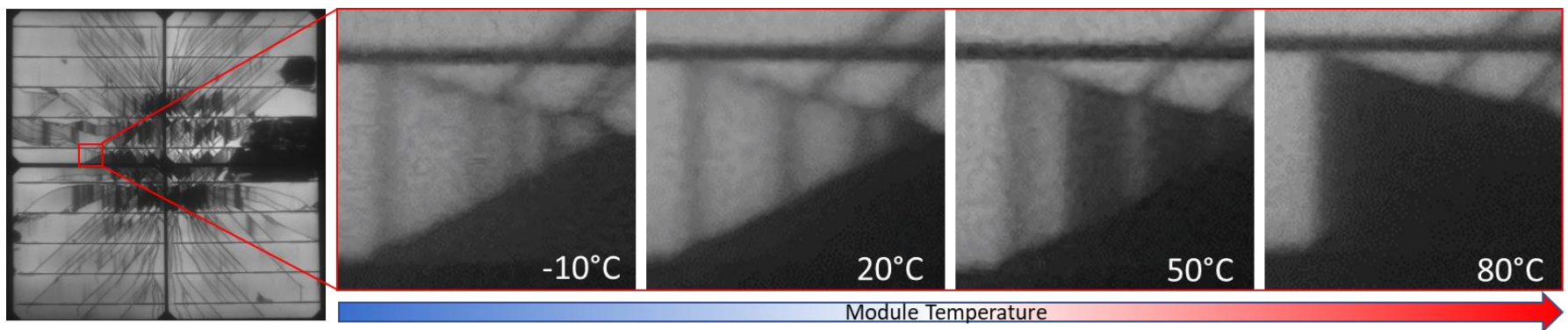

Fig. 6. In-situ electroluminescence at various temperatures for a severely cracked glass/glass module. The first image (full MiMo) is the initial condition at $-40^{\circ} \mathrm{C}$. A forward-bias current injection of 9.3A is used. Temperatures displayed are module temperature. Module temperatures shown are nominal values where actual temperatures are within $\pm 0.5^{\circ}$

failure to identify any damage at all.

The MiMo also exhibited cell cracks, the most significant of which is a crack which spans the width of the upper-left cell, running parallel to the cell tab. The cell area beneath the crack loses conductivity due to the presence of the damaged solder. Typically, given the location of the cell tab, such a crack would not have an immediate impact on cell performance because there is an immediate pathway to the conducting tab [4]. As temperature increases, so too, does the density of grid finger disconnections, that is likely a result of the crack width increasing due to displacement of the cells, like the behavior described in example 1 (Fig. 6)

Fig. 8 shows the EL images taken at the end of each 10 min dwell at $80^{\circ} \mathrm{C}$ for each cycle. Following cycle 3 , the lower part of the upper-left cell becomes darker than in cycles 1 and 2 , indicating a partial disconnection. The lower part of the cell remains disconnected through cycle 4 , but by the end of cycle 5 the cell area has seemingly reconnected. There are two possible explanations for this behavior. The first is attributed to cell movement and crack realignment. Silverman et al [24] previously demonstrated the temperature-dependency of cell displacement within a PV laminate, which was found to move both parallel and perpendicular to the gridlines. Additionally, through scanning electron microscopy (SEM) it was shown that debris from the cracked cell or metallization could fall within the crack, preventing it from fully closing at lower temperatures. Debris falling into the crack due to cell displacement could explain the cracks inability to fully close after additional thermal cycles, thus severing connections to the grid metallization on the opposite side of the crack. Subsequent cycles could have then forced the debris out (or into a different position), allowing the cell to close, therefore reestablishing metallization connection. The second explanation could also be attributed to the movement of the cells and metallization, except this time relating more to the critical solder joint connecting the cell tab to the bus bar. The cell tab or solder joint could be moving in such a way that connections are temporarily remade. It's possible that the crack keeps the lower portion of the cell disconnected at the end of all cycles, but the state of the solder joint connection determines whether or not current can flow from that area of the cell or not. With a driving current at short-circuit current $\left(\mathrm{I}_{\mathrm{sc}}\right)$ or greater, large contrast is created. It is not possible to determine the actual effect on module power from the images alone. Future work will include 
in-situ current-voltage characterization to quantify the impact

that such cracks have on the module power.

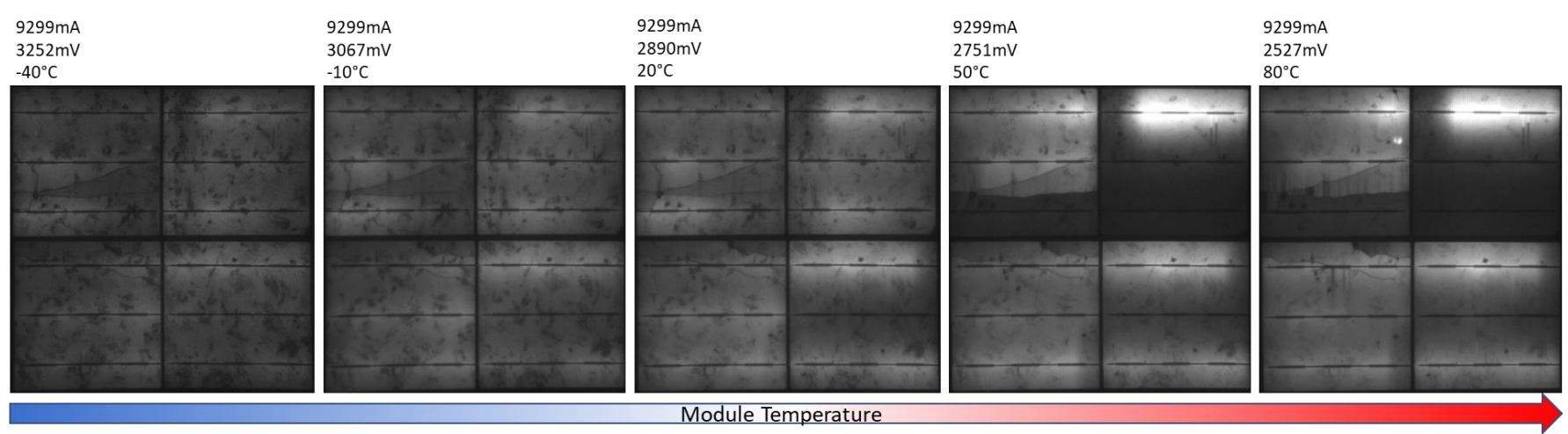

Fig. 7. In-situ EL imaging of a multi-crystalline (mc-Si) MiMo at various temperatures for a MiMo experiencing solder fatigue. Arrow represents the direction in module temperature change from $-40^{\circ} \mathrm{C}$ to $80^{\circ} \mathrm{C}$. Module temperatures shown are nominal values where actual temperatures are within $\pm 0.5^{\circ} \mathrm{C}$

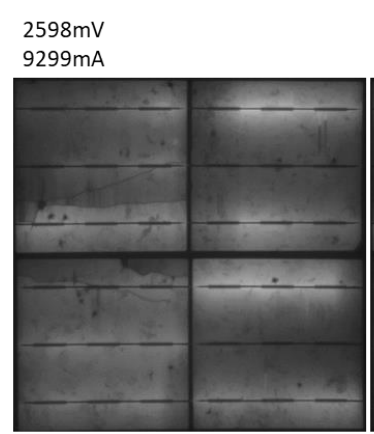

Cycle 1

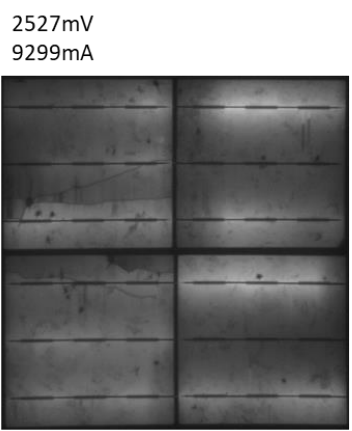

Cycle 2

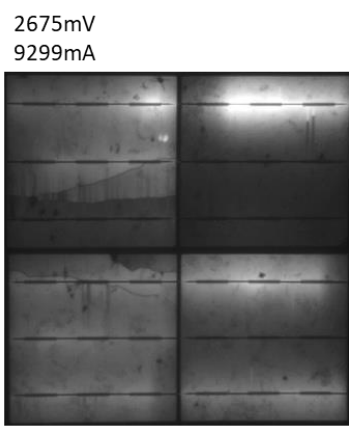

Cycle 3

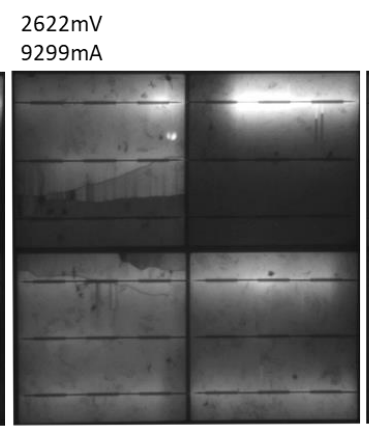

Cycle 4
$2519 \mathrm{mV}$

$9299 \mathrm{~mA}$

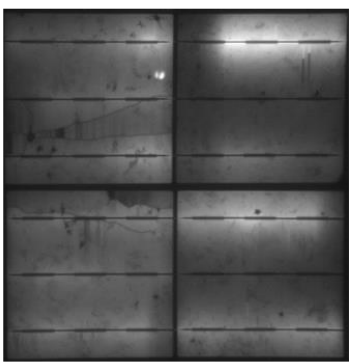

Cycle 5

Fig. 8. In-situ EL imaging of a mc-Si MiMo at $80^{\circ} \mathrm{C}$ following a 10-min dwell at the end of each thermal cycle (between $-40^{\circ} \mathrm{C}$ and $80^{\circ} \mathrm{C}$ )

\section{C) Example 3}

The third example given is from a monocrystalline $\mathrm{Si}$ cell MiMo with a glass front sheet, EVA encapsulant and polyvinylidene fluoride (PVDF)-based backsheet. The MiMo was subjected to testing in C-AST, through which it suffered cell cracking and partial cell disconnection. Here the MiMo is used to demonstrate the effect of temperature and mechanical loading on crack width. The MiMo was subjected to a temperature ramp from $-40^{\circ} \mathrm{C}$ to $80^{\circ} \mathrm{C}$ in $30^{\circ} \mathrm{C}$ steps. Following a 10 min dwell, an EL image is taken of the MiMo with no load. Subsequently, a mechanical load equivalent to $2400 \mathrm{~Pa}$ (static loading conditions according to IEC 61215 Module Quality Test 16 [18]) using the front-side ring-shaped mechanical actuators and the imaging at various temperatures was repeated.

Images are shown in Fig. 9. In this case, with increasing temperature and no mechanical load, the disconnected cell area in the bottom-right cell appears to regain connectivity which contradicts the behavior observed for examples 1 and 2 (Fig. 6 and 7). Mechanical loading appears to have a minimal effect on cell cracks at temperatures below $20^{\circ} \mathrm{C}$, with no significant change in connected cell area, grid finger connections or crack width observed. For temperatures $20^{\circ} \mathrm{C}$ and $50^{\circ} \mathrm{C}$, the effect of mechanical loading on the cell disconnections is more evident. The partially disconnected cell area becomes darker under mechanical load, indicating increased disconnection with loading. This is likely caused by the mechanical load driving apart the cell areas, widening the cell gap and resulting in loss of conductivity across the silver gridlines. Interestingly, at $80^{\circ} \mathrm{C}$, the effect of mechanical loading is negligible. This could be explained by the change in elastic properties of the EVA, at temperatures greater than $50^{\circ} \mathrm{C}$, EVA undergoes a rapid decrease in modulus of elasticity [25]. The reduced elasticity could reduce the strain transfer from the glass to the cells, such that the cells do not undergo significant displacement when mechanical load is applied. A finite-element model is currently being developed by Hartley et al [12] to study this behavior. 


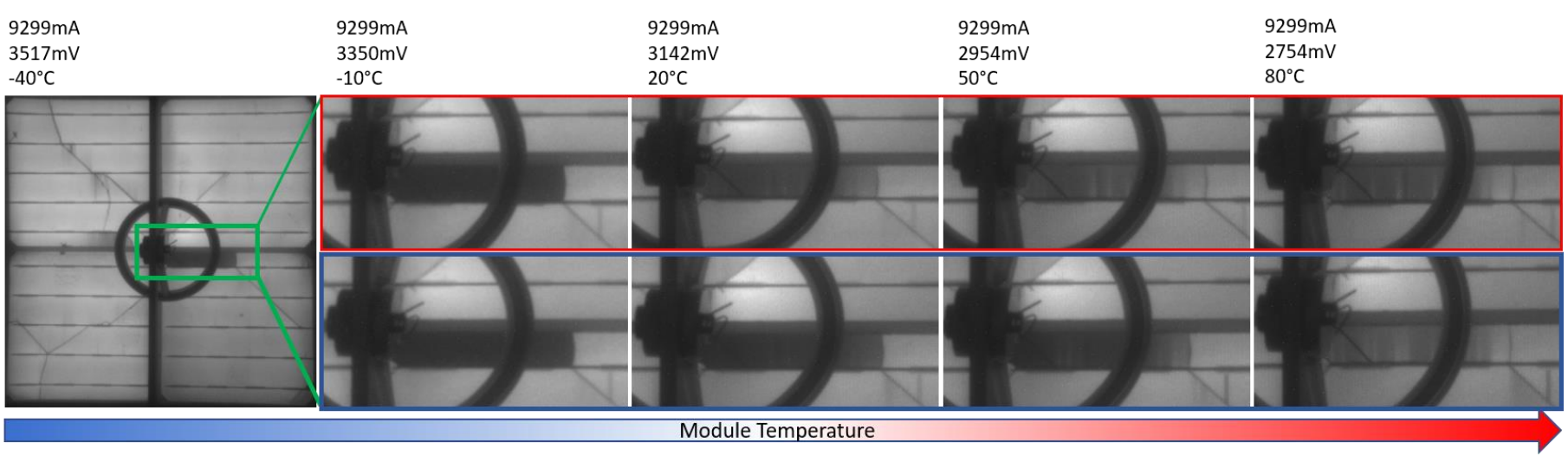

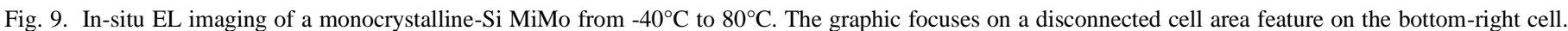

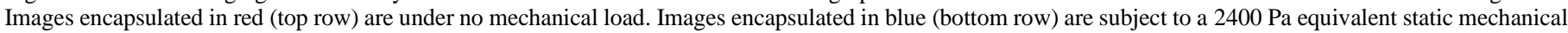
load. Arrow represents the direction in module temperature change. Module temperatures shown are nominal values where actual temperatures are within $\pm 0.5^{\circ} \mathrm{C}$

\section{DISCUSSION}

In section III it was shown that the EL imaging setup could identify cell cracks and solder/interconnect fatigue in the test modules used in this study. Three examples were given from damaged modules characterized at temperature conditions beyond STC. The test samples used in this work were minimodules with a $2 \times 2$ cell configuration. Mechanical loading applied to the mini-modules was displacement-controlled with a ring-shaped actuator. With the exception of the sample in example 1 , the degree of displacement was determined such that the total displacement at the center of the sample would be equivalent to the total displacement at the center of a 60-cell module under $2400 \mathrm{~Pa}$ load. Example 1 was subject to more severe loading to induce severe cell cracking. The load applied to example 1 may not be representative of real loading conditions caused by wind or snow. Future work is being conducted to verify that the bending moments and the applied stress to the cells in test are relevant to full-size modules. Assuming that the applied stresses are valid for example 2 and 3 , we would expect the behavior of cell cracks in mini-modules to be comparable to those in full-size modules.

The degradation modes observed in this work are commonly observed field-failure modes in full-size PV modules. The All-India Survey 2018 conducted EL imaging on 700 fielded PV modules [26]. It is shown that cell cracking is prevalent throughout the modules examined, even in those with less than 5 years in the field. While some modules only exhibit micro-cracks with minimal effect on the power of the module, several modules demonstrate cracking which has propagated such that large areas of the cells are disconnected, greatly affecting power loss. The cell cracking demonstrated in the report is similar to that which was observed in Fig. 7 and Fig. 8. The EL survey in the All-India report also shows examples of modules that have suffered from apparent ribbon interconnect or solder joint degradation. Similar to Fig. 7 and Fig. 8, failure of an interconnect is shown to shift current-flow to a more functional interconnect, thus leading to a dark area of the cell corresponding to the area of the failed interconnect. Similar degradation modes have also been reported for fielded PV modules in other locations [27]. Here it was also shown that interconnect fatigue could lead to secondary, more destructive failure modes such as hot spots in the field, further accelerated module power loss.

It was shown that the effects of solder/interconnect fatigue and cell cracking may be temperature-dependent. In the case of solder fatigue/interconnect failure, the condition may be exacerbated at elevated temperatures, and, for the example provided, when characterizing at temperatures close to STC temperature there was no observable evidence of damage. In the case of cell cracking, it is shown that there is a temperature dependency, however, the behavior is more complex. The examples provided were contradictory in that one MiMo exhibited an increasing cell disconnection with increasing temperature, while a second MiMo exhibited decreasing cell disconnection with increasing temperature. Furthermore, it was shown that for one MiMo, the total disconnected area of a cell would vary when subjected to additional thermomechanical loading. The long-term effects of cracked solar cells in PV modules is not yet fully understood. The results presented in this paper have shown that the behavior of cell cracks is quite complex, and that future endeavors to quantify the power loss associated with cell cracks should consider these complexities. The EL cameras in the C-AST apparatus will serve to understand how cracks propagate as a function of the various stress factors applied, and under which conditions these cracks open to result in power loss.

\section{V.CONCLUSIONS}

Here we have demonstrated a method for characterizing cell defects in PV modules using in-situ EL imaging within an environmental chamber. A low-cost and low-profile CMOSbased camera has been identified that produces good quality EL images even on full-sized modules, allowing for the identification of cracks and other cell defects. A thermally isolating housing was developed to allow the cameras to be mounted within the environmental chamber without risk of damage from overheating or excess humidity exposure. The housing and specially developed heat exchanger maintain camera temperatures at $25^{\circ} \mathrm{C} \pm 3^{\circ} \mathrm{C}$. 
It was demonstrated that some degradation modes, such as cell cracking and solder fatigue/interconnect failure, show a strong dependence on external stressors such as temperature and mechanical loading. EL characterization of PV modules within a restricted temperature range, therefore, limits the visual information obtained. Additionally, while no examples were identified in the test samples here, it is anticipated that other electrical degradation modes such as grid finger corrosion and light-induced degradation modes could be detected in susceptible cells.

Limiting the characterization of PV modules to a single temperature following aging could yield results that potentially lead to premature certification of module designs. The possible power loss of the modules as it relates to the observed defects is not quantified in this work, but EL characterization of modules at a wider range of temperatures is recommended as some cell defects may not be evident or may be underestimated at STC temperature immediately following aging and it is not fully understood what the long-term effects of those defects might be. The method outlined in this work could also help to further our understanding of crack initiation, development and behavior when PV cells are subject to different mechanical loading and environmental conditions.

\section{ACKNOWLEDGEMENT}

The authors would like to thank Karl G. Bedrich for his valuable insights. This work was supported by the U.S. Department of Energy (DOE) under Contract No. DE-AC3608GO28308 with Alliance for Sustainable Energy, LLC, the Manager and Operator of the National Renewable Energy Laboratory (NREL). NREL is a national laboratory of the DOE, Office of Energy Efficiency and Renewable Energy. Funding provided as part of the Durable Modules Consortium (DuraMAT), an Energy Materials Network Consortium funded by the U.S. Department of Energy, Office of Energy Efficiency \& Renewable Energy, Solar Energy Technologies Office. The views expressed in the article do not necessarily represent the views of the DOE or the U.S. Government. Instruments and materials are identified in this paper to describe the experiments. In no case does such identification imply recommendation or endorsement by NREL. The U.S. Government retains and the publisher, by accepting the article for publication, acknowledges that the U.S. Government retains a nonexclusive, paid-up, irrevocable, worldwide license to publish or reproduce the published form of this work, or allow others to do so, for U.S. Government purposes.

\section{REFERENCES}

[1] International Electrotechnical Commision, "IEC 60904-1 Photovoltaic Devices Part 1: Measurement of Photovoltaic CurrentVoltage Characteristics." 2006.

[2] M. Köntges, S. Kajari-Schröder, I. Kunze, and U. Jahn, "Crack Statistic of Crystalline Silicon Photovoltaic Modules," in Proceedings of 25th European PV Solar Energy Conference, 2011, vol. 26, pp. 3290-3294.

[3] S. Pingel, Y. Zemen, O. Frank, T. Geipel, and J. Berghold,
"Mechanical stability of solar cells within solar panels," in Proceedings of 24th European PV Solar Energy Conference, 2009, pp. 3459-3464.

[4] M. Kontges, I. Kunze, S. Kajari-Schroder, X. Breitenmoser, and B. Bjørneklett, "The risk of power loss in crystalline silicon based photovoltaic modules due to micro-cracks," Sol. Energy Mater. Sol. Cells, vol. 95, no. 4, pp. 1131-1137, Apr. 2011.

[5] U. Eitner, M. Kontges, and R. Brendel, "Use of digital image correlation technique to determine thermomechanical deformations in photovoltaic laminates: Measurements and accuracy," Sol. Energy Mater. Sol. Cells, vol. 94, no. 8, pp. 1346-1351, Aug. 2010.

[6] M. W. Rowell, S. G. Daroczi, D. W. J. Harwood, and A. M. Gabor, "The Effect of Laminate Construction and Temperature Cycling on the Fracture Strength and Performance of Encapsulated Solar Cells," pp. 3927-3931, 2018.

[7] A. M. Gabor, R. Janoch, A. Anselmo, J. L. Lincoln, and H. Seigneur, "Mechanical Load Testing of Solar Panels - Beyond Certification Testing," 2016 IEEE 43rd Photovolt. Spec. Conf., pp. 3574-3579, 2016

[8] D. C. Jordan, T. J. Silverman, B. Sekulic, and S. R. Kurtz, "PV Degradation Curves: Non-Linearities and Failure Modes," in Proceedings of 32nd European PV Solar Energy Conference and Exhibition, 2016.

[9] M. Owen-Bellini, P. Hacke, S. Spataru, D. C. Miller, and M. D. Kempe, "Combined-Accelerated Stress Testing for Advanced Reliability Assessment of Photovoltaic Modules," in 35th European PV Solar Energy Conference and Exhibition, 2018.

[10] M. Owen-Bellini, D. B. Sulas-Kern, S. Spataru, H. North, G. Perrin, and P. Hacke, "In-Situ Performance characterization of photovoltaic modules during combined-accelerated stress testing," in 46th IEEE Photovoltaics Specialist Conference, 2019.

[11] J. Meert, "Simulating Photovoltaic Mini-Modules; SAND20198484 C," in Sandia Student Intern Symposium, 2019.

[12] J. Y. Hartley et al., "Effects of Photovoltaic Module Materials and Design on Module Deformation Under Load," IEEE J. Photovoltaics, pp. 1-6, 2020.

[13] S. Spataru, P. Hacke, and M. Owen-Bellini, "CombinedAccelerated Stress Testing System for Photovoltaic Modules," in Proceedings of 45th IEEE Photovoltaics Specialists Conference, 2018.

[14] K. G. Bedrich, M. Bliss, T. R. Betts, and R. Gottschalg, "Electroluminescence Imaging of PV Devices : Camera Calibration and Image Correction," 2016 IEEE 43rd Photovolt. Spec. Conf., pp. 1532-1537, 2016.

[15] G. Bradski, “The OpenCV Library," Dr. Dobb's J. Softw. Tools, 2000.

[16] T. E. Oliphant, A guide to NumPy (Vol.1.). Trelgol Publishing, 2006.

[17] K. N. Ermakov, N. A. Ivanov, O. V. Lobanov, V. V. Pashuk, M. G. Tverskoy, and S. M. Lyubinskii, "Experimental investigation of the effect of high-energy protons on charge-coupled devices," Tech. Phys. Lett., vol. 36, no. 7, pp. 610-612, 2010.

[18] International Electrotechnical Commision, "IEC 61215-2: Crystalline Silicon Terrestrial Photovoltaic (PV) Modules-Design Qualification and Type Approval," International Electrotechnical Commission. Geneva, 2016.

[19] M. Koehl, M. Heck, S. Wiesmeier, and J. Wirth, "Modeling of the nominal operating cell temperature based on outdoor weathering," Sol. Energy Mater. Sol. Cells, vol. 95, no. 7, pp. 1638-1646, Jul. 2011.

[20] S. Kurtz et al., "Evaluation of high-temperature exposure of photovoltaic modules," Prog. Photovoltaics Res. Appl., vol. 19, no. 8, pp. 954-965, 2011.

[21] P. Hacke et al., "Combined and sequential accelerated stress testing for derisking photovoltaic modules," in Advanced Nano- and Micro-Materials for Photovoltaics: Future and Emerging Technologies, Amsterdam: Elsevier, 2019.

[22] K. Hartman et al., "Validation of Advanced Photovoltaic Module Materials and Processes by Combined-Accelerated Stress Testing (C-AST)," in 46th IEEE Photovoltaics Specialist Conference, 2019. U. Eitner, S. Kajari-Schröder, M. Köntges, and H. Altenbach, 
"Thermal Stress and Strain of Solar Cells in Photovoltaic Modules," in Shell-like Structures: Non-classical Theories and Applications, H. Altenbach and A. V. Eremeyev, Eds. Berlin,

Heidelberg: Springer Berlin Heidelberg, 2011, pp. 453-468.

[24] T. J. Silverman, M. Bliss, A. Abbas, T. Betts, M. Walls, and I.

Repins, "Movement of Cracked Silicon Solar Cells During Module

Temperature Changes," in 46th IEEE Photovoltaics Specialist

Conference, 2020, pp. 1517-1520.

[25] M. Owen-bellini, D. Montiel-chicharro, J. Zhu, T. R. Betts, and R.

Gottschalg, "Influence of Viscoelastic Properties of Encapsulation

Materials on the Thermomechanical Behavior of Photovoltaic

Modules," vol. 8, no. 1, pp. 183-188, 2018.

[26] Shashwata and R. D. Chattopadhyay, "All-India Survey of Photovoltaic Module Reliability : 2018," 2018.

[27] J. Rand, M. Reed, and R. Flottemesch, "New Field Testing

Protocol: Monitoring DC Health," in NREL Photovoltaic Reliability Workshop 2019, 2019.

Pursuant to the DOE Public Access Plan, this document represents the authors' peer-reviewed, accepted manuscript. The published version of the article is available from the relevant publisher. 